University of Windsor

Scholarship at UWindsor

2016

\title{
Energetic physiology mediates individual optimization of breeding phenology in a migratory Arctic Seabird
}

Holly L. Hennin

University of Windsor

Joël Bêty

Pierre Legagneux

Hugh G. Gilchrist

Tony D. Williams

See next page for additional authors

Follow this and additional works at: https://scholar.uwindsor.ca/biologypub

Part of the Biology Commons

\section{Recommended Citation}

Hennin, Holly L.; Bêty, Joël; Legagneux, Pierre; Gilchrist, Hugh G.; Williams, Tony D.; and Love, Oliver P., "Energetic physiology mediates individual optimization of breeding phenology in a migratory Arctic Seabird" (2016). American Naturalist, 188, 4, 434-445.

https://scholar.uwindsor.ca/biologypub/1222

This Article is brought to you for free and open access by the Department of Biological Sciences at Scholarship at UWindsor. It has been accepted for inclusion in Biological Sciences Publications by an authorized administrator of Scholarship at UWindsor. For more information, please contact scholarship@uwindsor.ca. 


\section{Authors}

Holly L. Hennin, Joël Bêty, Pierre Legagneux, Hugh G. Gilchrist, Tony D. Williams, and Oliver P. Love 


\title{
Energetic Physiology Mediates Individual Optimization of Breeding Phenology in a Migratory Arctic Seabird
}

\author{
Holly L. Hennin, ${ }^{1}$ Jöel Bêty, ${ }^{2}$ Pierre Legagneux, ${ }^{2}$ H. Grant Gilchrist, ${ }^{3}$ \\ Tony D. Williams, ${ }^{4}$ and Oliver P. Love ${ }^{1, \star}$
}

1. Department of Biological Sciences and Great Lakes Institute for Environmental Research, University of Windsor, Windsor, Ontario N9B 3P4, Canada; 2. Département de Biologie, Chimie, et Géographie and Centre d'Études Nordiques, Université du Québec, Rimouski, Quebec G5L 3A1, Canada; 3. Environment and Climate Change Canada, National Wildlife Research Centre, Carleton University, Ottawa, Ontario K1A 0H3, Canada; 4. Department of Biological Sciences, Simon Fraser University, 8888 University Drive, Burnaby, British Columbia V5A 156, Canada

Submitted March 11, 2016; Accepted May 19, 2016; Electronically published August 1, 2016

ABSTRACT: The influence of variation in individual state on key reproductive decisions impacting fitness is well appreciated in evolutionary ecology. Rowe et al. (1994) developed a condition-dependent individual optimization model predicting that three key factors impact the ability of migratory female birds to individually optimize breeding phenology to maximize fitness in seasonal environments: arrival condition, arrival date, and ability to gain in condition on the breeding grounds. While empirical studies have confirmed that greater arrival body mass and earlier arrival dates result in earlier laying, no study has assessed whether individual variation in energetic management of condition gain effects this key fitness-related decision. Using an 8-year data set from over 350 prebreeding female Arctic common eiders (Somateria mollissima), we tested this component of the model by examining whether individual variation in two physiological traits influencing energetic management (plasma triglycerides: physiological fattening rate; baseline corticosterone: energetic demand) predicted individual variation in breeding phenology after controlling for arrival date and body mass. As predicted by the optimization model, individuals with higher fattening rates and lower energetic demand had the earliest breeding phenology (shortest delays between arrival and laying; earliest laying dates). Our results are the first to empirically determine that individual flexibility in prebreeding energetic management influences key fitness-related reproductive decisions, suggesting that individuals have the capacity to optimally manage reproductive investment.

Keywords: individual optimization, breeding phenology, fattening rate, energetic management, triglycerides, glucocorticoids.

\section{Introduction}

Life-history trade-offs are driven by the allocation of limited resources to multiple life-history traits and decisions (Stearns

\footnotetext{
* Corresponding author; e-mail: olove@uwindsor.ca.

ORCIDs: Hennin, http://orcid.org/0000-0001-8327-1102; Gilchrist, http:// orcid.org/0000-0001-5031-5092.

Am. Nat. 2016. Vol. 188, pp. 434-445. (C) 2016 by The University of Chicago. 0003-0147/2016/18804-56853\$15.00. All rights reserved.

DOI: $10.1086 / 688044$
}

1992; McNamara and Houston 1996). As such, because individual state is predicted to be indicative of the amount of resources available to allocate to multiple life-history traits and decisions, it is thought to be a primary driver regulating individual optimization of life-history trade-offs (Stearns 1992; Kisdi et al. 1998; Moore and Hopkins 2009). In migratory avian species breeding in temporally constrained, seasonal environments, the timing of reproduction is an important fitness-related decision influencing the quantity and quality of an individual's investment (Perrins 1970; Smith 1993; Lepage et al. 2000; Garant et al. 2007; Brommer and Rattiste 2008) and therefore its subsequent reproductive success (Lepage et al. 2000; Love et al. 2010; Descamps et al. 2011). Individuals that can arrive earlier and in better condition are predicted to invest in reproduction earlier, produce more offspring with higher survival, and achieve higher reproductive success (Rowe et al. 1994; Kisdi et al. 1998; Morris 1998). The optimal combination of reproductive timing and reproductive investment is thought to result from the trade-off of delaying reproduction to invest in additional offspring (greater reproductive investment) and the declining value of offspring as the breeding season progresses (diminished gains from reproductive investment due to later timing of reproduction; Drent and Daan 1980; Rowe et al. 1994; Morris 1998; Lepage et al. 2000; Bêty et al. 2003).

To develop testable hypotheses for the assumed relationships between timing of arrival and body condition at arrival on the breeding grounds, timing of laying, and investment in reproduction (i.e., clutch size), Rowe et al. (1994) formalized a condition-dependent individual optimization model largely centered around migratory birds breeding in seasonal environments (fig. 1, based on figs. 1-5 in Rowe et al. 1994). The model predicts that individuals arriving from migration to the breeding grounds earlier and in better body condition (i.e., higher body mass or size-corrected body mass) have the potential to acquire the local resources they need to fuel re- 


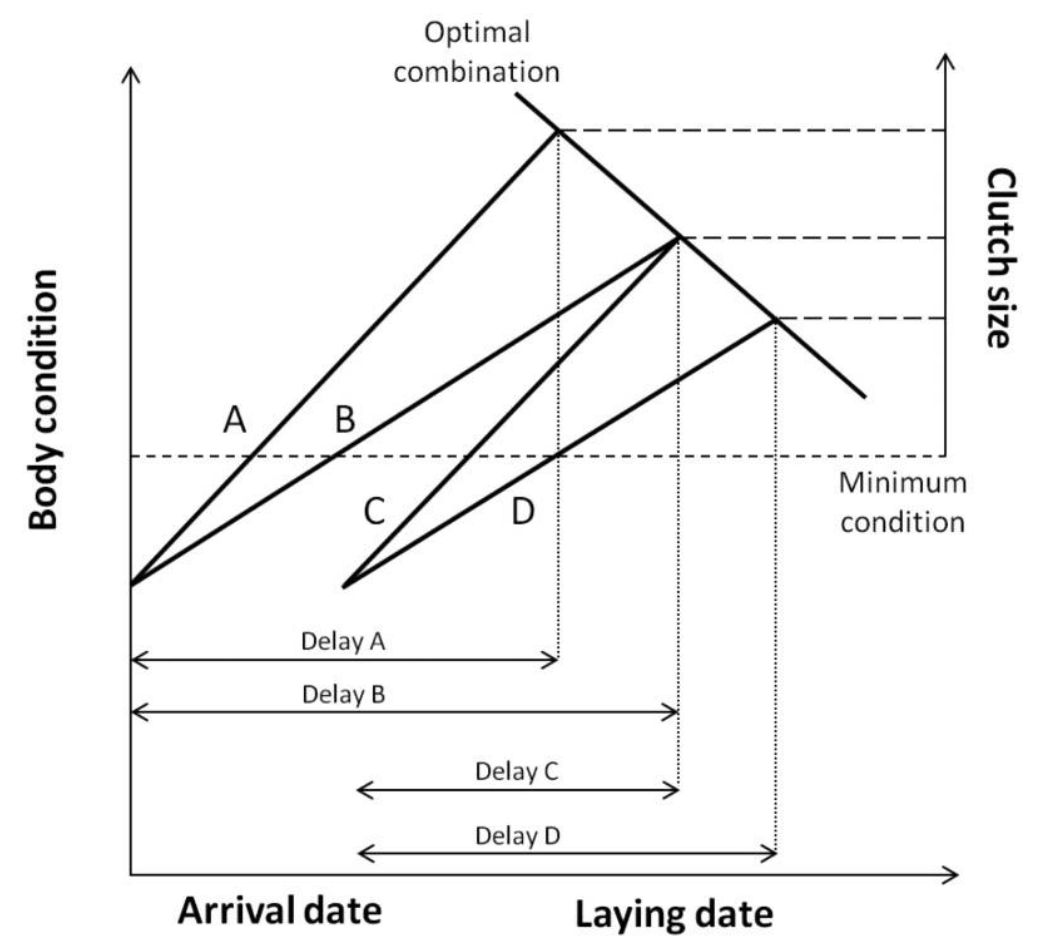

Figure 1: Condition-dependent individual optimization model (adapted from Bêty et al. 2003). The short-dashed horizontal line indicates the body-condition threshold at which individuals can invest in and commit to reproduction. The upward-diagonal solid lines represent individual gains in condition leading up to their optimal combinations of laying date and breeding investment (represented by the downward-diagonal solid line). The vertical dotted lines indicate predicted laying dates, and the horizontal long-dashed lines indicate predicted investment (clutch size). The letters represent the potential outcomes for individuals with varying fattening rates (slopes). Individuals with a higher rate of condition gain during prebreeding should meet the optimal combinations earlier (shorter delay) and lay earlier (A vs. B and C vs. D; Rowe et al. 1994) and potentially mitigate the effects of late arrival (B vs. C) or poorer body condition after arrival on the breeding grounds.

production earlier and therefore initiate reproduction earlier, a key fitness-related parameter in many avian species (Drent and Daan 1980; Rowe et al. 1994; Lepage et al. 2000; Bêty et al. 2003; Descamps et al. 2011). Although applied in insect (Johansson and Rowe 1999), mammal (Dobson and Michner 1995; Marrow et al. 1996; Morris 1998), reptile (Doughty 1996; Doody et al. 2003), and fish (Cargnelli and Neff 2006; Poulos and McCormick 2015) systems, the model's ultimate goal is to examine the mechanisms behind the well-known seasonal decline in clutch size in many avian species, where earlier laying dates should be associated with greater investment in reproduction (i.e., clutch size; Drent and Daan 1980; Rowe et al. 1994; Bêty et al. 2003; Descamps et al. 2011). Independent of arrival date and condition, Rowe et al. (1994) also made a second set of important predictions that, to date, have received far less attention in the literature. They predicted that once on the breeding grounds, individuals with the ability to gain in condition faster (i.e., optimize energetic management) and therefore fuel investment in reproduction sooner should be able to lay earlier, even after controlling for variation in arrival date and body mass (see figs. 4, 5 in Rowe et al. 1994). The biological implications of this prediction suggest that even females arriving with lower body mass or at a later date but able to efficiently manage their energetics (i.e., quickly accumulate resources needed for reproduction) may be able to lay earlier and invest more in reproduction than previously appreciated (fig. 1, scenario A vs. B and $C$ vs. D). Although there have been some empirical tests of this optimization model with regard to arrival date and body mass at arrival on the breeding grounds (Bêty et al. 2003; Descamps et al. 2011), a substantial amount of variation in reproductive decisions remains unexplained. Unfortunately, it has been difficult to empirically test for the effects of individual variation in the prebreeding rates of condition gain directly, since this requires the capture of free-living individuals twice to assess condition gain (e.g., before birds initiate follicle recruitment and immediately after they commence laying) while mitigating the well-known effects of capture stress on breeding activities (Love et al. 2004; Buttler et al. 2011; Legagneux et al. 2012).

Physiological traits have long been viewed as central regulators of key life-history decisions (Ketterson and Nolan 
1999; Williams 2008). Measures of energetic physiology in particular have been proposed as prime candidates for mediating underlying individual variation in reproductive decisions, because they are mechanistic proxies of individual state and can require the capture of an individual only once (Zera and Harshman 2001; Ricklefs and Wikelski 2002; Harshman and Zera 2007; Zera et al. 2007). Plasma levels of triglycerides (TRIG) and baseline glucocorticoids (GCs) in particular have recently been identified for their potential role in influencing reproductive decisions (Williams 2012; Love et al. 2014; Hennin et al. 2015) and may therefore be useful for empirically testing predictions of conditiondependent models in free-living species.

Plasma TRIG is a metabolite present in very-low-density lipoprotein, which increases following foraging and is the primary method in which fat is deposited to adipose tissues (Gibbons et al. 2004). Plasma TRIG titers from one sample have been shown to correlate positively with increases in body mass in bats (McGuire et al. 2009), turtles (Price et al. 2013), and many free-living and captive avian species including warblers (e.g., Jenni-Eiermann and Jenni 1994; Jenni and Jenni-Eiermann 1996; Jenni and Schwilch 2001), shorebirds (Williams et al. 1999; Cerasale and Guglielmo 2006; Lyons et al. 2008), and ducks (Anteau and Afton 2008). As such, in many avian species, a single sample of plasma TRIG has been useful for characterizing the accumulation of fat stores (Jenni-Eiermann and Jenni 1994; Cerasale and Guglielmo 2006) and rate of gain in condition (Williams et al. 1999). However, once oviparous females begin growing their follicles in preparation for ovulation (known as the rapid follicular growth phase), females undergo a mechanistic shift from producing TRIG for somatic fattening to producing yolk-targeted very-low-density lipoprotein for lipid deposition to the yolks of eggs (Salvante and Williams 2002; Salvante et al. 2007; Williams 2012). Therefore, to use plasma TRIG as a relevant measure of physiological fattening, it is critical to know the exact breeding stage of a given individual.

Largely studied for their role in the stress response, glucocorticoids (GCs) are a group of pleiotropic hormones that at baseline levels (i.e., measured within fewer than 3 min postcapture; Wingfield et al. 1982; Schoech et al. 1999; Romero and Reed 2005), play very important roles in managing daily and seasonal energetic demand (Dallman et al. 1993; Romero 2002; Landys et al. 2006; Crespi et al. 2013), largely by maintaining homeostasis through their role in gluconeogenesis (Sapolsky et al. 2000; McEwan and Wingfield 2003). Baseline GCs are often elevated to support the predictable energetic demands of specific life-history stages (e.g., reproduction; Dallman et al. 1993; Romero 2002; Landys et al. 2006; Crespi et al. 2013). Recent correlative and manipulative studies examining baseline corticosterone (CORT; the primary avian glucocorticoid) have indicated that it increases prior to reproduction to potentially fulfill a preparatory role for the energetic demands ahead (Love et al. 2014; Hennin et al. 2015), likely due to the relationship between baseline CORT, foraging behavior, and fat deposition (Holberton 1999; Landys et al. 2004; Lõhmus et al. 2006; Angelier et al. 2007a; Holberton et al. 2007; Crossin et al. 2012; Hennin et al. 2016). Indeed, experimental increases in baseline levels of CORT have been shown to directly, causally influence increases in body mass, likely via increased foraging behavior and fat deposition (Hennin et al. 2016). Nonetheless, since baseline GCs have pleiotropic effects on other endocrine pathways (e.g., the hypothalamic-pituitary-gonadal axis; Miller et al. 2009), elevations even within a baseline range can potentially impact the functioning of other traits and endocrine pathways. Therefore, given that individuals must manage baseline GC elevations carefully to optimize impacts across endocrine systems, baseline CORT is a prime candidate for influencing both changes in body mass and overall energetic management in individuals that are preparing to invest in reproduction. By sampling individuals prior to committing to reproductive investment and measuring both the instantaneous physiological fattening rate (plasma TRIG) and a driver of energetic demand (baseline plasma CORT), we have the potential to quantify the mechanisms mediating the ability of individuals to optimize energetic management to mechanistically test Rowe et al.'s (1994) conditiondependent individual optimization model.

Here we use data on plasma TRIG and baseline CORT collected from over 350 prebreeding Arctic-breeding female common eiders (Somateria mollissima) across 8 years to empirically test whether individual variation in prebreeding energetic physiology (fattening rates and energetic management) influences the timing of breeding within the context of the condition-dependent individual optimization model (Rowe et al. 1994; Bêty et al. 2003). Capital breeding birds use only endogenous fat stores to fuel reproduction, whereas income breeders use resources acquired solely from local, immediate foraging (Stephens et al. 2009). Common eiders have a mixed, capital-income breeding strategy using a combination of stored endogenous resources and resources acquired from current, local foraging to grow their follicles and therefore must feed intensively during the prebreeding period (Sénéchal et al. 2011). As such, female common eiders are an ideal system for examining the energetic physiological mechanisms mediating reproductive decisions because they $(i)$ must reach a body mass threshold to initiate follicle growth (Sénéchal et al. 2011; Hennin et al. 2015); (ii) must acquire enough endogenous resources to fuel a 24-day incubation period in which they fast (Bottitta et al. 2003), otherwise risking nest abandonment (Bustnes and Erikstad 1991); (iii) reproduce within a highly seasonal environment and therefore must optimally time reproduction to maximize reproductive success (Love et al. 2010); and (iv) have previously been shown to be a model species for testing predictions of 
condition-dependent individual optimization models (e.g., the causal relationship between prebreeding body condition and laying date was shown experimentally; Descamps et al. 2011).

To empirically test whether the rate of condition gain measured through energetic physiology influences breeding phenology, we separated the model into two testable components as predicted by Rowe et al. (1994): (i) the delay before laying (time required to sufficiently gain in condition and reach the optimal combinations of laying date and breeding investment) and (ii) the relative laying date (fig. 1). Although the relative laying date and delay before laying metrics are related, they describe different, important aspects of reproduction as well as testable components of the optimization model. Relative lay date specifically indicates the timing of reproduction, whereas the delay before laying indicates the amount of time individuals require to gain in body mass (i.e., fat stores) after migration, meet the minimum body mass threshold required to initiate reproduction, grow follicles, and ultimately begin laying their clutch. Based on Rowe et al.'s (1994) condition-dependent individual optimization model, two potential predictions of the way in which variation in energetic physiology could influence the optimization of breeding phenology decisions can be made, after controlling for the known influence of arrival date and body condition (i.e., body mass). First, individuals with overall higher physiological fattening rates (plasma TRIG) and high signals of energetic demand (high CORT to induce foraging) could result in higher rates of condition gain and therefore earlier breeding phenology (a shorter delay prior to laying and earlier relative laying dates). Alternatively, given that individuals must balance the benefits and costs of elevated baseline GCs carefully (Love et al. 2014; Crossin et al. 2015), one could also predict that individuals able to manage their energetic physiology more efficiently (i.e., the ability to maximize physiological fattening while minimizing elevations of baseline CORT) may in fact exhibit the earliest breeding phenology.

\section{Material and Methods}

\section{Study Site and General Field Methods}

Our study site is located in the East Bay Migratory Bird Sanctuary on Mitivik Island, Nunavut, Canada $\left(64^{\circ} 02^{\prime} \mathrm{N}\right.$, $81^{\circ} 47^{\prime} \mathrm{W}$ ), and is Canada's largest colony of Arctic-nesting common eiders (up to 9,000 pairs annually). Females winter along the coast of Newfoundland and Labrador or off the western coast of Greenland (Mosbech et al. 2006), initiate spring migration in mid-May, arrive on the breeding grounds in mid-June, and initiate laying in late June and early July (Love et al. 2010; Hennin et al. 2015). From 2006 to 2013 , we captured prerecruiting females $(N=366)$ op- portunistically using flight nets early in the season during mid-June to early July as they visited the colony. Since we targeted the timing of capture to coincide with the timing of arrival on the breeding grounds (Love et al.2010), we used individual capture date as a useful proxy for their timing of arrival at the colony (Descamps et al. 2011; see "Discussion").

Within 3 min of a female flying into the flight net, a blood sample was taken from the tarsal vein using a 1-mL heparinized syringe and 23-g thin-wall, 0.5 -inch needle to obtain baseline physiology (Wingfield et al. 1982; Schoech et al. 1999; Romero and Reed 2005). Across all years, blood samples were collected at all times of day. Although baseline CORT and TRIG have been shown to exhibit diel variation in secretion in temperate-breeding species (e.g., Dallman et al. 1993; Jenni and Jenni-Eiermann 1996), Arctic common eiders at our study site do not exhibit these diel trends during the breeding season (Steenweg et al. 2015), allowing us to include all collected blood samples in analyses. Blood samples were transferred to a heparinized collecting tube and centrifuged for $10 \mathrm{~min}$ at $10,000 \mathrm{rpm}$, and the separated plasma and red blood cells were stored at $-20^{\circ} \mathrm{C}$ in the field $\left(-80^{\circ} \mathrm{C}\right.$ in the lab) until further analysis. After sampling, body mass (in grams) was collected, and females were banded and given a unique combination of plastic, colored nasal tags for future identification. Nasal tags were attached with an ultraviolet degradable monofilament to ensure that the tags would fall off at the end of the breeding season, prior to fall migration. Although wing-bar measurements have been used to assign age to hens in other species and populations (e.g., Carney 1992), this technique is unreliable for hens nesting at Mitivik Island (H. G. Gilchrist, unpublished manuscript), and as such, we were unable to accurately assign age to our hens.

Breeding activities of the individuals within our eider colony are monitored yearly using spotting scope-based observations from seven permanent blinds. Behavioral observations of hens (e.g., nest searching, laying, incubating) were collected using consistent protocols and trained observers. Using these observation techniques, the nests of nasaltagged hens were monitored twice daily to collect accurate laying dates (transformed into relative laying dates; individual Julian lay date relative to the median laying date of the colony that year; Lepage et al. 2000), which allowed for the calculation of the delay before laying (number of days between arrival and laying dates).

\section{Physiological Assays}

Plasma triglycerides (TRIG) were measured using a commercially available kit (Sigma-Aldrich, Oakville, Ontario, Canada; Williams et al. 1999) optimized for use in prebreeding common eiders (Hennin et al. 2015). Following dilu- 
tion, samples were added to 96-well microplates with reagent A to measure free glycerol, followed by reagent B to measure total glycerol. After the addition of each reagent, the plates were shaken for $10 \mathrm{~min}$ at $37^{\circ} \mathrm{C}$ and then read using a plate reader at $540 \mathrm{~nm}$. The amount of triglycerides $\left(\mathrm{mmol} \mathrm{L}{ }^{-1}\right.$ ) in the plasma was calculated by subtracting the amount of free glycerol (first read) from the amount of total glycerol (second read). Each plate was run with a commercially available internal plasma control (Sigma-Aldrich) and a serially diluted standard curve of glycerol standard $\left(2.54 \mathrm{mmol} \mathrm{L}^{-1}\right)$. Inter- and intra-assay coefficients of variation were $11.27 \%$ and $4.42 \%$ for total TRIG and $5.51 \%$ and $6.29 \%$ for free glycerol, respectively.

Baseline plasma corticosterone (CORT) was measured using a commercially available, previously validated enzyme immunoassay kit based on competitive binding (EIA; Assay Designs/Enzo Scientific, Ann Arbor, MI) and optimized for common eiders (Hennin et al. 2015). Samples were run unextracted and in triplicate at a 1:20 dilution with 1.5\% steroid displacement buffer. Each assay plate was run with a standard curve by serially diluting a 200,000-pg $\mathrm{mL}^{-1}$, kitprovided corticosterone standard and a corticosterone-spiked control sample and read at $405 \mathrm{~nm}$ using a plate reader (for details, see Hennin et al. 2015). The inter- and intraassay coefficients of variation across all plates were $8.54 \%$ and $5.87 \%$, respectively.

\section{Statistical Analyses}

Analyses for the delay before laying and relative laying date were restricted to include only prerecruiting females. Females were classified as prerecruiting if they were caught 8 days or longer before laying, since these birds would not yet have begun rapidly growing follicles (Alisauskas and Ankney 1992; Hennin et al. 2015). Birds caught within 7 days of laying have already committed to follicle growth (i.e., investment in eggs; Hennin et al. 2015) and instead would be categorized to the rapid follicle growth stage. In instances where females were recaptured in different years (only 32 in over 350 birds included in our study), we included only the first instance of her capture in which we were able to assay baseline CORT and TRIG. All subsequent captures were excluded to prevent statistical bias.

We tested the effect of four (independent) covariates using generalized linear mixed models: female body mass at arrival; relative arrival date (the date the individual arrived relative to the colony median arrival date for that year); mass-corrected TRIG, which is an index of physiological fattening rate (Williams et al. 1999); and baseline CORT (log transformed) on delay before the laying and relative laying date of individuals. Since the relationship between fattening rate and baseline CORT may vary depending on current energetics and breeding stage (Hennin et al. 2015), we also examined the potential for an interaction between fattening rate and baseline CORT in our analyses. Due to the inclusion of mass-corrected TRIG in our analyses to represent fattening rate, we did not include interactions between body mass and energetic physiology. Finally, we included year as a random factor in all analyses to account for annual variation in reproductive decisions and physiology, in addition to other extrinsic factors. Our analyses were conducted in R (R Development Core Team 2014) using the unrestricted maximum likelihood method of the lme4 package (Bates et al. 2012). We then used the corrected Akaike information criterion (AICc) and Akaike weights to select the most parsimonious model for each independent variable. The model with the lowest AICc value was considered to be the most parsimonious, and models found to be within two $\triangle$ AICc units were considered competing models (Burnham and Anderson 2002). Finally, we used model averaging (multimodel inference) to estimate parameters, as it reduces bias and increases precision (Burnham and Anderson 2002). All values are presented as mean \pm SEM unless otherwise stated.

\section{Results}

For the delay before laying, body mass was present in all competing models, with the interaction between fattening rate and baseline CORT being present in the top two models (table 1). Females with heavier body mass at arrival and those with higher fattening rates combined with lower levels of baseline CORT had the shortest delays before laying (table 2; fig. 2a, 2b). Year as a random factor explained $4.48 \%$ of the overall variance. For relative laying date, both body mass and relative arrival date were present in all competing models, and the interaction between baseline CORT and fattening rate was present in the top model (table 1). According to the parameter estimates, individuals with a heavier body mass at arrival laid earlier, and those with higher fattening rates combined with lower levels of baseline CORT had the earliest laying dates (table 2; fig. $2 c$, $2 d)$. Year as a random factor explained $18.4 \%$ of the overall variance.

\section{Discussion}

We examined a highly relevant but previously untested component of Rowe et al.'s (1994) condition-dependent individual optimization model - the impact of individual variability in the rate of gain in condition mediated through energetic management on breeding phenology. We predicted that after controlling for the known influences of arrival date and body mass, including information on prebreeding energetic management (physiological fattening and baseline levels of plasma CORT) would enhance our ability to predict reproductive 
Table 1: Results of model selection on the delay before laying and the relative laying date of prerecruiting female common eiders breeding at Mitivik Island

\begin{tabular}{|c|c|c|c|c|}
\hline & Log likelihood & $k$ & $\Delta \mathrm{AICc}$ & $w_{i}$ \\
\hline \multicolumn{5}{|l|}{ Delay before laying: } \\
\hline Mass + Arrival + CORT $\times$ FatRate & -511.23 & 8 & $.00^{\mathrm{a}}$ & $.23^{*}$ \\
\hline Mass + CORT $\times$ FatRate & -512.39 & 7 & .15 & $.21 *$ \\
\hline Mass & -516.16 & 4 & 1.28 & .12 \\
\hline Mass + Arrival & -515.25 & 5 & 1.56 & $.10^{*}$ \\
\hline Mass + FatRate & -515.46 & 5 & 1.99 & $.08^{*}$ \\
\hline Mass + Arrival + FatRate & -514.58 & 6 & 2.37 & .07 \\
\hline Mass + CORT & -515.94 & 5 & 2.96 & .05 \\
\hline Mass + Arrival + CORT & -515.09 & 6 & 3.38 & .04 \\
\hline Mass + Arrival + CORT + FatRate & -514.40 & 7 & 4.17 & .03 \\
\hline CORT $\times$ FatRate & -518.82 & 6 & 10.84 & .00 \\
\hline Arrival + CORT $\times$ FatRate & -517.98 & 7 & 11.32 & .00 \\
\hline Null & -523.89 & 3 & 14.66 & .00 \\
\hline CORT & -523.01 & 4 & 14.99 & .00 \\
\hline FatRate & -523.89 & 4 & 15.32 & .00 \\
\hline Arrival & -523.32 & 4 & 15.60 & .00 \\
\hline Arrival + FatRate & -522.64 & 5 & 16.35 & .00 \\
\hline \multicolumn{5}{|l|}{ Relative lay date: } \\
\hline Mass + Arrival + CORT $\times$ FatRate & -516.93 & 8 & $.00^{\mathrm{b}}$ & $.26^{*}$ \\
\hline Mass + Arrival & -520.22 & 5 & .12 & $.25^{*}$ \\
\hline Mass + Arrival + FatRate & -519.28 & 6 & .36 & .22 \\
\hline Mass + Arrival + CORT & -520.21 & 6 & 2.22 & .09 \\
\hline Mass + Arrival + CORT + FatRate & -519.27 & 7 & 2.50 & .07 \\
\hline Arrival + CORT $\times$ FatRate & -525.31 & 7 & 14.57 & .00 \\
\hline Arrival & -529.29 & 4 & 16.15 & .00 \\
\hline Arrival + FatRate & -528.42 & 5 & 16.51 & .00 \\
\hline Mass + CORT $\times$ FatRate & -555.81 & 7 & 75.57 & .00 \\
\hline Mass & -559.23 & 4 & 76.01 & .00 \\
\hline Mass + FatRate & -558.71 & 5 & 77.10 & .00 \\
\hline Mass + CORT & -558.97 & 5 & 77.60 & .00 \\
\hline CORT $\times$ FatRate & -562.99 & 6 & 87.78 & .00 \\
\hline Null & -566.74 & 3 & 88.95 & .00 \\
\hline FatRate & -566.23 & 4 & 90.03 & .00 \\
\hline CORT & -566.74 & 4 & 91.04 & .00 \\
\hline
\end{tabular}

Note: Log likelihood, number of parameters $(k)$, change in corrected Akaike information criterion ( $\triangle$ AICc), and AICc weight $\left(w_{i}\right)$ are provided for each competing model. Independent variables in the models include body mass at capture (Mass), relative arrival date (Arrival), baseline corticosterone values (CORT), and mass-corrected triglyceride values representing fattening rate (FatRate). Year was included as a random factor. A model with an interaction also included corresponding parameters. Competing models $(<2.0 \Delta \mathrm{AICc})$ display $w_{i}$ values with an asterisk.

${ }^{\mathrm{a}} \mathrm{AICc}=1,039.25$

${ }^{\mathrm{b}} \mathrm{AICc}=1,050.66$

phenology parameters associated with the condition-dependent individual optimization model. We predicted that the earliest laying dates and shortest delays before laying (earliest breeding phenology) would result from higher physiological fattening rates coupled to either higher or lower baseline CORT, the former prediction being related to the known role of elevated baseline CORT in mediating foraging and the latter being related to individual efficiency in optimizing the cost-benefit ratio of elevated baseline CORT levels. We found support for the second prediction: female common eiders with higher fattening rates and lower baseline CORT (higher energetic physiology efficiency) had the earliest breeding phenology. As such, being able to fatten at a high rate (high TRIG) in preparation for reproduction in response to low signals of energetic demand (low baseline CORT; i.e., higher efficiency) appears to provide the optimal physiological phenotype that maximizes investment in reproduction with regard to reproductive phenology. Nonetheless, females unable to maintain high physiological fattening rates appear to be able to achieve moderately earlier breeding phenology 
Table 2: Summary of model-averaged parameter estimates and unconditional standard errors for parameters included in the delay before laying and relative laying date analyses

\begin{tabular}{lrrrr}
\hline & \multicolumn{1}{c}{$\beta$} & SE & Min 95\% CI & Max 95\% CI \\
\hline Delay before laying: & & & & \\
$\quad$ Intercept & 23.91 & 2.90 & 18.22 & 29.61 \\
Arrival & -.10 & .07 & -.24 & .04 \\
Mass & -5.12 & 1.33 & -7.73 & -2.50 \\
CORT & -.11 & .25 & -.60 & .38 \\
FatRate & -.05 & .04 & -.14 & .04 \\
CORT $\times$ FatRate & .09 & .04 & .02 & .16 \\
Relative lay date: & & & & \\
Intercept & 18.58 & 2.93 & 12.80 & .64 \\
Arrival & .78 & .08 & .63 & .94 \\
Mass & -5.67 & 1.32 & -8.30 & .54 \\
CORT & .05 & .25 & -.40 & .03 \\
FatRate & -.06 & .05 & -.20 & .15 \\
CORT $\times$ FatRate & .08 & .00 & .01 & \\
\hline
\end{tabular}

Note: The parameters are the same independent variables as described in the note for table 1 . CI $=$ confidence interval; $\operatorname{Max}=$ maximum; Min = minimum

by compensating with higher baseline CORT, which could drive increases in absolute foraging rates (see "Introduction"; fig. 2). Regardless of the interaction with baseline CORT, and as predicted by Rowe et al.'s (1994) conditiondependent individual optimization model (fig. 1), lower fattening rates (low TRIG) consistently resulted in the longer delays before laying and the latest relative laying dates. It therefore appears that variation in the timing of arrival and arrival body mass can be fine-tuned by individually optimized strategies for acquiring resources on the breeding grounds and hence driving the accrual of endogenous fat stores in preparation for reproduction.

\section{A Novel Test of the Individual Optimization Model}

Previous empirical work testing predictions of Rowe's condition-dependent individual optimization model have focused on the impacts of arrival condition (measured only as body mass) and arrival date on breeding phenology. Both correlative and manipulative studies in free-living species have confirmed that individuals arriving with heavier body mass, or those arriving at an earlier date, or a combination of both, can initiate breeding the earliest (Bêty et al. 2003; Descamps et al. 2011). Given a number of logistical constraints of working in free-living systems, a key additional prediction that a faster gain in condition should positively influence the timing of breeding (breeding phenology) remained largely untested in the wild. While food supplementation studies can influence fattening rates and reveal some of the relationships between individual body mass, reproductive timing, and reproductive investment (Schoech et al. 2009; Ruffino et al. 2014), other parameters such as territory quality and competition can be influenced simultaneously, often making results difficult to interpret (Williams 2012) By employing highly relevant metrics of energetic physiology, we confirmed this long-held prediction of Rowe's model; after controlling for arrival date and body mass, females with higher instantaneous physiological fattening (i.e., greater rate of condition gain and slope; higher plasma TRIG/physiological fattening rate), regardless of their energetic demand (baseline CORT), had a shorter delay before laying as well as an earlier relative laying date (fig. 1, scenario A or C). These results have important implications for how life-history investment decisions evolve. At the simplest level, our results suggest that certain physiological or behavioral phenotypes may enable individuals to gain condition quickly on the breeding grounds following arrival from migration. Alternatively, individual females may have differing degrees of physiological or behavioral flexibility, enabling them to adjust their foraging behavior (the rate at which they forage, the locations that they forage within, or both; e.g., Bond and Esler 2006) based on a combination of intrinsic and extrinsic conditions to optimally adjust their breeding phenology independently of their arrival date and condition. For instance, in a food supplementation study of Florida scrub jays (Aphelocoma coerulescens; Schoech et al. 2009), baseline CORT was more tightly related to the timing of breeding in bad compared to good years. However, it is important to note that this species is cooperative and an income breeder and therefore under very different energetic demands than eiders. Moreover, the study was not able to measure the rate of gain in body mass or fat stores, verifying it as a driver of laying date. As such, to test for differences between the two potential mechanisms, physiological manipulations in freeliving individuals will be necessary. Although an important output of Rowe's model, we were currently unable to test 
a)

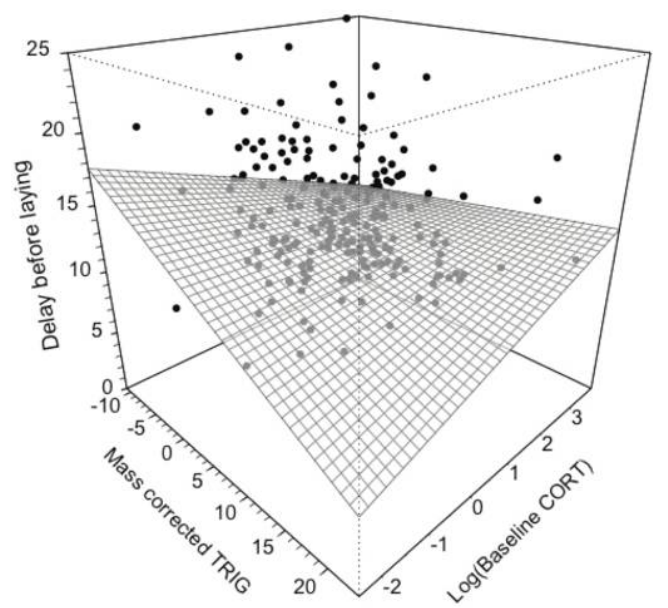

c)

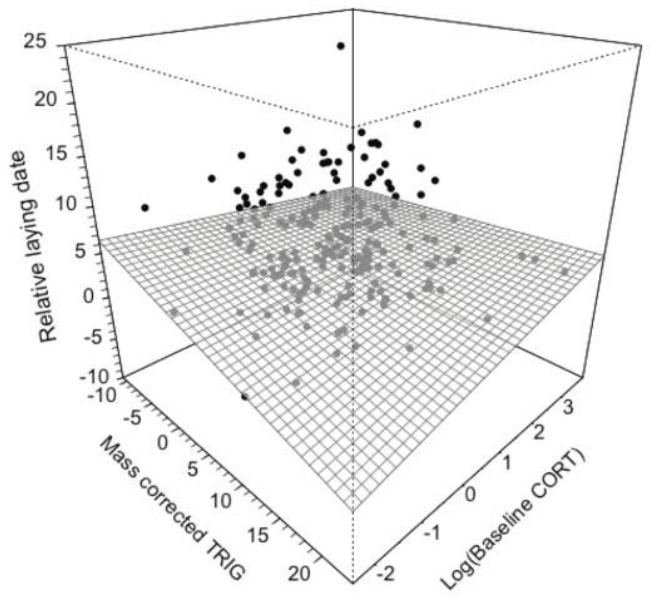

b)

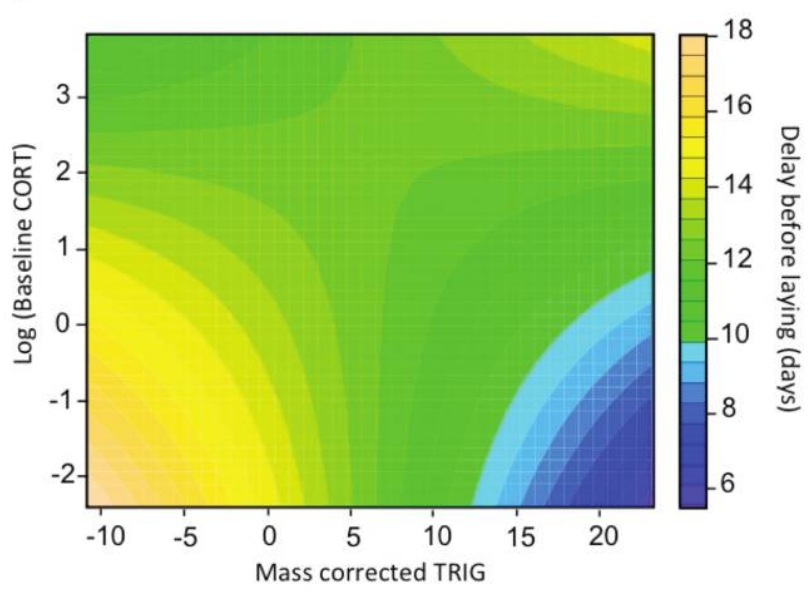

d)

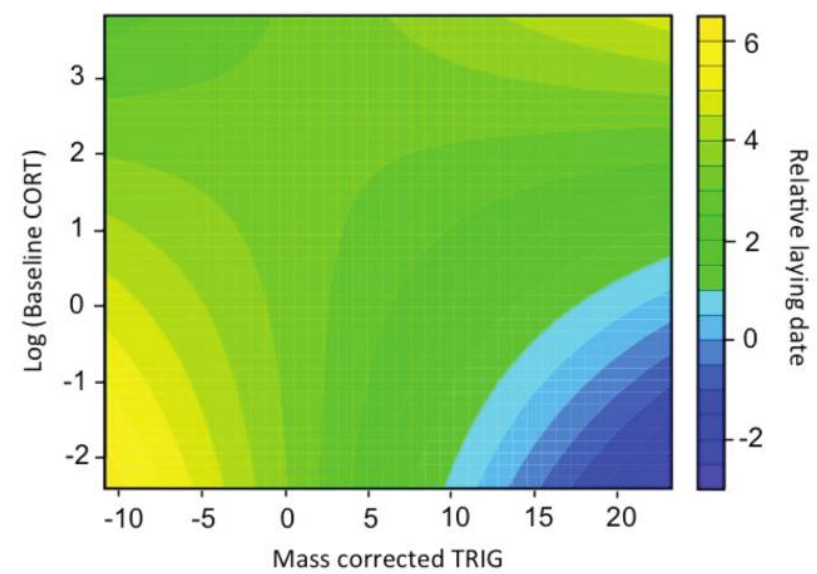

Figure 2: Interaction between the baseline corticosterone (CORT; log transformed) and the fattening rate (residuals between plasma triglycerides [TRIG] and body mass) on the delay before laying $(a, b)$ and the relative lay date $(c, d)$. The interactions are illustrated with 3D $(a, c)$ and 2D $(b, d)$ graphs, with the grids in the 3D plots and the contour plots both representing the same model-corrected values (corrected for relative arrival date and body mass). The dots in the 3D plots represent the raw values to compare to the model-corrected values (grids). The $2 \mathrm{D}$ contour plots represent the distribution of the delay before laying or the relative lay date (each color represents 0.5 days) in relation to the baseline CORT and the fattening rate.

the impact of variation in the rate of condition gain on reproductive investment (i.e., clutch size) due to the difficulty of acquiring accurate estimates of clutch size for most females nesting at our study site within the current 8-year data set (2006-2013). However, the links between prebreeding body mass, arrival date, and seasonal decline in clutch size have already been demonstrated in mixed-strategy Arcticbreeding species including common eiders (Bêty et al. 2003; Descamps et al.2011). What remains to be examined is whether higher fattening rates per se during prebreeding and optimization of energetic management result in larger clutch sizes, as predicted by Rowe et al. (1994).

\section{Influence of Energetic Physiology on the Optimal Timing of Reproduction}

We found that the impact of a high fattening rate on both the delay before laying and the laying date was dependent on an individual's ability to manage its energetics (i.e., baseline CORT levels). There may be two potential ways in which these physiologically mediated effects on laying decisions could arise, both operating through differences in individually optimized breeding strategies across females (with associated downstream costs and benefits). First, it is well known that the energetic physiology of long-lived vertebrates 
changes over the life span of an individual (Monclús et al. 2011; Elliott et al. 2014). Age-related changes in baseline CORT (Heidinger et al. 2006; Monclús et al. 2011; Riechert et al. 2012) and physiological sensitivity to the effects of baseline CORT (Peiffer et al. 1991; Reul et al. 1991; Perlman et al. 2007) have also been documented in a number of vertebrate species. Consequently, age-related variation may directly shape the relationship between energetic physiological traits and reproductive decisions (Heidinger et al. 2006; Monclús et al. 2011; Riechert et al. 2012). We are currently unable to reliably determine age in our study species; however, an ability to do so in the future or to work in a colony of known-age birds would allow further testing of the impact of age-related changes in the reproductive sensitivity to variation in baseline CORT on investment decisions.

Second, independent of age-related effects on energetic physiology, inherent individual variation in the secretion of baseline CORT, behavioral (i.e., foraging) sensitivity to baseline CORT (Angelier et al. 2007b; Crossin et al. 2012), the acquisition and assimilation of energetic resources (Bond and Esler 2006; Heath et al. 2010; Rigou and Guillemette 2010), and the ability to optimally mitigate the costs of migration (Crossin et al.2010) could all work together to fine-tune general optimal investment strategies (Williams 2008, 2012). For example, those individuals able to maintain baseline GCs at lower levels given similar life-history costs may have the highest inherent quality, exhibiting greater energetic physiological efficiency and therefore gaining higher fitness benefits (Angelier et al. 2010). Alternatively, interindividual variation in the ability to manage energetic physiology under varying environmental conditions (i.e., physiological flexibility) could result in different individual-based optimization strategies within the same life-history stage (Angelier et al. 2007b; Schultner et al. 2013; Love et al. 2014). For example, we found that while having high energetic physiology efficiency (high physiological fattening rates and low baseline CORT) may be optimal for an individual if it is achievable, females may still be able to optimize laying decisions to a degree via higher physiological fattening rates coupled with elevated baseline CORT, although this strategy would be predicted to come at a hypothesized cost given the impacts of elevated GCs on oxidative damage (Constantini et al. 2011), ultimately leading to reduced life spans (Bize et al. 2008). Within this framework, it is possible that late-laying birds with low fattening rates and low CORT may be adopting a slower pace-of-life strategy, resulting in a lower intra-annual probability of reproductive success and a potentially smaller amount of within-season investment (i.e., smaller clutch sizes) but benefiting from a longer life span (Comendant et al. 2003; Lancaster et al. 2008; Descamps et al. 2011; Palacios et al. 2012). Alternatively, these individuals may simply be poorer in quality, with lower energetic physiological efficiency, and therefore may have more difficulty in recovering from winter- ing and migration, resulting in carry-over effects delaying their subsequent reproductive attempt (Crossin et al. 2010). While all biologically valid and relevant, these hypotheses remain to be tested in free-living species since they necessitate the difficulties of hormonally manipulating prebreeding females and then consistently following short- and longterm benefits or costs to reproduction or survival within females across multiple years. Captive studies involving the prebreeding manipulations of baseline CORT would also be helpful to minimize the impacts of external sources of variation, potentially influencing the interaction between baseline CORT and physiological fattening while still moving individuals outside of their optimal physiological phenotype to examine underlying costs on a per-individual basis.

\section{Conclusions and Future Research}

The inclusion of energetic physiology, representing individual variation in energetic management (plasma TRIG and baseline CORT), during the prerecruiting period allowed us to investigate a previously untested component of the condition-dependent individual optimization model first proposed by Rowe et al. (1994). Although the influence of these physiological traits on reproductive decisions was relatively complex, their inclusion enhanced the predictive capacity of the model and improved our interpretation of how variation in individual physiological phenotypes influences reproductive decisions that impact fitness. To determine whether these mechanisms have a causal effect on breeding phenology and breeding investment and to examine whether variation in their physiological control mechanisms drives investment trade-offs, future research should aim to manipulate baseline CORT or plasma TRIG levels within biologically relevant levels in free-living individuals during the critical prebreeding stage (Crossin et al. 2015). Being able to couple these metrics with measures of foraging behavior (i.e., foraging rates and profitability) and monitoring long-term success (i.e., survival) would greatly improve our appreciation for how underlying mechanisms enable individually optimized life-history strategies to evolve.

\section{Acknowledgments}

We thank the 2006-2013 East Bay field crews for data collection and I. Butler and R. Kelly for data organization. We also thank the Natural Sciences and Engineering Research Council of Canada, Environment Canada, the Nunavut Wildlife Management Board, the Polar Continental Shelf Project, the Canadian Network of Centres of Excellence (ArcticNet), and Polar Knowledge Canada for logistical support and research or personal funding. All procedures have been approved via Environment Canada (NUN-SCI-11-04, NUNMBS-11-05), the territory of Nunavut (WL 2011-029), the 
University of Windsor Committee for Animal Care (AUPP 11-06; Reproductive Strategies of Arctic-Breeding Common Eiders), and Environment Canada Animal Care (EC-PN-15 -026).

\section{Literature Cited}

Alisauskas, R. T., and C. D. Ankney. 1992. The cost of egg laying and its relationship to nutrient reserves in waterfowl. Pages 30-61 in B. D. J. Batt, A. D. Afton, M. G. Anderson, C. D. Ankney, D. H. Johnson, J. A. Kadlec, and G. L. Krapu, eds. Ecology and management of breeding waterfowl. University of Minnesota Press, Minneapolis.

Angelier, F., C. Clement-Chastel, G. W. Gabrielsen, and O. Chastel. 2007a. Corticosterone and time-activity budget: an experiment with black-legged kittiwakes. Hormones and Behavior 52:482491.

Angelier, F., B. Moe, H. Weimerskirch, and O. Chastel. 2007b. Agespecific reproductive success in a long-lived bird: do older parents resist stress better? Journal of Animal Ecology 76:1181-1191.

Angelier, F., J. C. Wingfield, H. Weimerskirch, and O. Chastel. 2010. Hormonal correlates of individual quality in a long-lived bird: a test of the "corticosterone-fitness hypothesis." Biology Letters 6:846849 .

Anteau, M. J., and A. D. Afton. 2008. Using plasma-lipid metabolites to index changes in lipid reserves of free-living lesser scaup (Aythya affinis). Auk 125:354-357.

Bates, D., M. Maechler, and B. Bolker. 2012. lme4: linear mixed-effects models using S4 classes. R package version 0.999999-0. http:// CRAN.R-project.org/package $=\operatorname{lme} 4$.

Bêty, J., G. Gauthier, and J.-F. Giroux. 2003. Body condition, migration, and the timing of reproduction in snow geese: a test of the condition-dependent model of optimal clutch size. American Naturalist 162:110-121.

Bize, P., G. Devevey, P. Monaghan, B. Doligez, and P. Christe. 2008. Fecundity and survival in relation to resistance to oxidative stress in a free-living bird. Ecology 89:2584-2593.

Bond, J. C., and D. Esler. 2006. Nutrient acquisition by female harlequin ducks prior to spring migration and reproduction: evidence for body mass optimization. Canadian Journal of Zoology 84:12231229.

Bottitta, G. E., E. Nol, and H. G. Gilchrist. 2003. Effects or experimental manipulation of incubation length on behaviour and body mass of common eiders in the Canadian Arctic. Waterbirds 26:100107.

Brommer, J. E., and K. Rattiste. 2008. "Hidden" reproductive conflict between mates in a wild bird population. Evolution 62:2326-2333.

Burnham, K. P., and D. R. Anderson. 2002. Model selection and multimodel inference: a practical information-theoretic approach. Springer, New York.

Bustnes, J. O., and K. E. Erikstad. 1991. Parental care in the common eider (Somateria mollissima): factors affecting abandonment and adoption of young. Canadian Journal of Zoology 69:1538-1545.

Buttler, E. I., H. G. Gilchrist, S. Descamps, R. M. Forbes, and C. Soos. 2011. Handling stress of female common eiders during avian cholera outbreaks. Lournal of Wildlife Management 75:283-288.

Cargnelli, L. M., and B. D. Neff. 2006. Condition-dependent nesting in bluegill sunfish Lepomis macrochirus. Iournal of Animal Ecology 75:627-633.
Carney, S. M. 1992. Species, age and sex identification of ducks using wing plumage. US Department of the Interior/US Fish and Wildlife Service, Washington, DC

Cerasale, D. J., and C. G. Guglielmo. 2006. Dietary effects on prediction of body mass changes in birds by plasma metabolites. Auk 123:836-846.

Comendant, T., B. Sinervo, E. I. Svensson, and J. Wingfield. 2003. Social competition, corticosterone and survival in female lizard morphs. Journal of Evolutionary Biology 16:948-955.

Constantini, D., V. Marasco, and A. P. Møller. 2011. A meta-analysis of glucocorticoids as modulators of oxidative stress in vertebrates. Lournal of Comparative Physiology B: Biochemical, Systems, and Environmental Physiology 181:447-456.

Crespi, E. J., T. D. Williams, T. S. Jessop, and B. Delehanty. 2013. Life history and the ecology of stress: how do glucocorticoid hormones influence life-history variation in animals? Functional Ecology 27:93-106.

Crossin, G. T., O. P. Love, S. J. Cooke, and T. D. Williams. 2015. Glucocorticoid manipulation in free-living animals: considerations of dose delivery, life-history context and reproductive state. Functional Ecology 30:116-125.

Crossin, G. T., P. N. Trathan, R. A. Phillips, A. Dawson, F. Le Bouard, and T. D. Williams. 2010. A carryover effect of migration underlies individual variation in reproductive readiness and extreme egg size dimorphism in macaroni penguins. American Naturalist 176:357-366

Crossin, G. T., P. N. Trathan, R. A. Phillips, K. B. Gorman, A. Dawson, K. Q. Sakamoto, and T. D. Williams. 2012. Corticosterone predicts foraging behavior and parental care in macaroni penguins. American Naturalist 180:E31-E41.

Dallman, M. F., A. M. Strack, S. F. Akana, M. J. Bradbury, E. S. Hanson, K. A. Scribner, and M. Smith. 1993. Feast and famine: critical role of glucocorticoids with insulin in daily energy flow. Frontiers in Neuroendocrinology 14:303-347.

Descamps, S., J. Bêty, O. P. Love, and H. G. Gilchrist. 2011. Individual optimization of reproduction in a long-lived migratory bird: a test of the condition-dependent model of laying date and clutch size. Functional Ecology 25:671-681.

Dobson, F. S., and G. R. Michener. 1995. Maternal traits and reproduction in Richardson's ground squirrels. Ecology 76:851-862.

Doody, J. S., A. Georges, and J. E. Young. 2003. Twice every second year: reproduction in the pig-nosed turtle, Carettochelys insculpta, in the wet-dry tropics of Australia. Journal of Zoology 259:179-188.

Doughty, P. 1996. Allometry of reproduction in two species of gekkonid lizards (Gehyra): effects of body size miniaturization on clutch and egg sizes. Journal of Zoology 240:703-715.

Drent, R. H., and S. Daan. 1980. The prudent parent: energetic adjustments in avian breeding. Ardea 68:225-252.

Elliott, K. H., J. F. Hare, M. Le Valliant, A. J. Gaston, Y. RopertCoudert, and W. G. Anderson. 2014. Ageing gracefully: physiology but not behaviour declines with age in a diving seabird. Functional Ecology 29:219-228.

Garant, D., L. E. B. Kruuk, R. H. McCleery, and B. C. Sheldon. 2007. The effects of environmental heterogeneity on multivariate selection on reproductive traits in female great tits. Evolution 61:1546-1559.

Gibbons, G. F., D. Wiggins, A. M. Brown, and A. M. Hebbachi. 2004 Synthesis and function of hepatic very-low-density lipoprotein. Biochemical Society Transactions 32:59-64.

Harshman, L. G., and A. J. Zera. 2007. The cost of reproduction: the devil in the details. Trends in Ecology and Evolution 22:80-86. 
Heath, J. P., H. G. Gilchrist, and R. C. Ydenberg. 2010. Interactions between rate processes with different timescales explain counterintuitive foraging patterns of Arctic wintering eiders. Proceedings of the Roval Society B: Biological Sciences 277:3179-3186.

Heidinger, B. J., I. C. T. Nisbet, and E. D. Ketterson. 2006. Older parents are less responsive to a stressor in a long-lived seabird: a mechanism for increased reproductive performance with age? Proceedings of the Roval Society B: Biological Sciences 273:2227-2231.

Hennin, H. L., P. Legagneaux, J. Bêty, T. D. Williams, H. G. Gilchrist, T. M. Baker, and O. P. Love. 2015. Pre-breeding energetic management in a mixed-strategy breeder. Oecologia 177:235-243.

Hennin, H. L., A. Wells-Berlin, and O. P. Love. 2016. Baseline glucocorticoids are drivers of body mass gain in a diving seabird. Ecology and Evolution 6:1702-1711. doi:10.1002/ece.1999.

Holberton, R. L. 1999. Changes in patterns of corticosterone secretion concurrent with migratory fattening in a Neotropical migratory bird. General and Comparative Endocrinology 116:49-58.

Holberton, R. L., C. M. Wilson, M. J. Hunter, W. B. Cash, and C. G. Sims. 2007. The role of corticosterone in suppressing migratory lipogenesis in the dark-eyed junco, Junco hyemalis: a model for central and peripheral regulation. Physiological and Biochemical Zoology 80:125-137.

Jenni, L., and S. Jenni-Eiermann. 1996. Metabolic responses to diurnal feeding patterns during the postbreeding, moulting and migratory periods in passerine birds. Functional Ecology 10:73-80.

Jenni, L., and R. Schwilch. 2001. Plasma metabolite levels indicate change in body mass in reed warblers Acrocephalus scirpaceus. Avian Sciences 1:55-65.

Jenni-Eiermann, S., and L. Jenni. 1994. Plasma metabolite levels predict individual body-mass changes in a small long-distance migrant, the garden warbler. Auk 111:888-899.

Johansson, F., and L. Rowe. 1999. Life history and behavioral responses to time constraints in a damselfly. Ecology 80:1242-1252.

Ketterson, E. D., and V. Nolan, Jr. 1999. Adaptation, exaptation, and constraint: a hormonal perspective. American Naturalist 154(suppl.) S4-S25.

Kisdi, É., G. Meszéna, and L. Pásztor. 1998. Individual optimization: mechanisms shaping the optimal reaction norm. Evolutionary Ecology 12:211-221.

Lancaster, L. T., L. C. Hazard, J. Clobert, and B. R. Sinervo. 2008. Corticosterone manipulation reveals differences in hierarchical organization of multidimensional reproductive trade-offs in $r$-strategist and K-strategist females. Journal of Evolutionary Biology 21:556565.

Landys, M. M., M. Ramenofsky, C. G. Guglielmo, and J. C. Wingfield. 2004. The low-affinity glucocorticoid receptor regulates feeding and lipid breakdown in the migratory Gambel's white-crowned sparrow Zonotrichia leucophrys gambelii. Journal of Experimental Biology 207:143-154.

Landys, M. M., M. Ramenofsky, and J. C. Wingfield. 2006. Actions of glucocorticoids at a seasonal baseline as compared to stress-related levels in the regulation of periodic life processes. General and Comparative Endocrinology 148:132-149.

Legagneux, P., P. L. F. Fast, G. Gauthier, and J. Bêty. 2012. Manipulating individual state during migration provides evidence for carry-over effects modulated by environmental conditions. Proceedings of the Roval Society B: Biological Sciences 279:876-883.

Lepage, D., G. Gauthier, and S. Menu. 2000. Reproductive consequences of egg-laying decisions in snow geese. Journal of Animal Ecology 69:414-427.
Lõhmus, M., L. F. Sundström, and F. R. Moore. 2006. Non-invasive corticosterone treatment changes foraging intensity in red-eyed vireos Vireo olivaceus. Journal of Avian Biology 37:523-526.

Love, O. P., C. W. Breuner, F. Vezina, and T. D. Williams. 2004. Mediation of a corticosterone-induced reproductive conflict. Hormones and Behavior 46:59-65.

Love, O. P., H. G. Gilchrist, S. Descamps, C. A. D. Semeniuk, and J. Bêty. 2010. Pre-laying climatic cues can time reproduction to optimally hatch offspring hatching and ice condition in an Arctic marine bird. Oecologia 164:277-286.

Love, O. P., C. L. Madliger, S. Bourgeon, C. A. D. Semeniuk, and T. D. Williams. 2014. Evidence for baseline glucocorticoids as mediators of reproductive investment in a wild bird. General and Comparative Endocrinology 199:65-69.

Lyons, J. E., J. A. Collazo, and C. G. Guglielmo. 2008. Plasma metabolites and migration physiology of semipalmated sandpipers: refuelling performance at five latitudes. Oecologia 155:417-427.

Marrow, P., J. M. McNamara, A. I. Houston, I. R. Stevenson, and T. H. Clutton-Brock. 1996. State-dependent life history evolution in Soay sheep: dynamic modelling of reproductive scheduling. Philosophical Transactions of the Roval Society B: Biological Sciences 351:17-32.

McEwan, B. S., and J. C. Wingfield. 2003. The concept of allostasis in biology and biomedicine. Hormones and Behaviour 43:2-15.

McGuire, L. P., M. B. Fenton, P. A. Faur, and C. G. Guglielmo. 2009. Determining feeding state and rate of mass change in insectivorous bats using plasma metabolite analysis. Physiological and Biochemical Zoology 82:812-818.

McNamara, J. M., and A. I. Houston. 1996. State-dependent life histories. Nature 380:215-221.

Miller, D. A., C. M. Vleck, and D. L. Otis. 2009. Individual variation in baseline and stress-induced corticosterone and prolactin levels predicts parental effort by nesting mourning doves. and Behavior 56:457-464.

Monclús, R., J. Tiulim, and D. T. Blumstein. 2011. Older mothers follow conservative strategies under predator pressure: the adaptive role of maternal glucocorticoids in yellow-bellied marmots. Hormones and Behavior 60:660-665.

Moore, I. T., and W. A. Hopkins. 2009. Interactions and trade-offs among physiological determinants of performance and reproductive success. Integrative and Comparative Biology 49:441-451.

Morris, D. W. 1998. State-dependent optimization of litter size. Oikos 83:518-528.

Mosbech, A., H. G. Gilchrist, F. Merkel, C. Sonne, A. Flagstad, and H. Nyegaard. 2006. Year-round movements of northern common eiders Somateria mollissima borealis breeding in Arctic Canada and West Greenland followed by satellite telemetry. Ardea 94:651-665.

Palacios, M. G., A. M. Sparkman, and A. M. Bronikowski. 2012. Corticosterone and pace of life in two life-history ecotypes of garter snake Thamnophis elegans. General and Comparative Endocrinology 175:443-448.

Peiffer, A., N. Barden, and M. J. Meaney. 1991. Age-related changes in glucocorticoid receptor binding and mRNA levels in the rat brain and pituitary. Neurobiology of Aging 12:475-479.

Perlman, W. R., M. J. Webster, M. M. Herman, J. E. Kleinman, and C. S. Weickert. 2007. Age-related difference in glucocorticoid receptor mRNA levels in the human brain. Neurobiology of Aging 28:447-458.

Perrins, C. M. 1970. The timing of birds' breeding seasons. Ibis 112: 242-255. 
Poulos, D. E., and M. I. McCormick. 2015. Asymmetries in body condition and order of arrival influence competitive ability and survival in a coral reef fish. Oecologia 179:719-728.

Price, E. R., T. T. Jones, B. P. Wallace, and C. G. Guglielmo. 2013. Serum triglycerides and $\beta$-hydroxybutyrate predict feeding status in green turtles (Chelonia mydas): evaluating a single blood sample method for assessing feeding/fasting in reptiles. Journal of Experimental Marine Biology and Ecology 439:176-180.

R Development Core Team. 2014. R: a language and environment for statistical computing. R Foundation for Statistical Computing, Vienna. http://www.R-project.org.

Reul, J. M., J. Rothuizen, and E. R. de Kloet. 1991. Age-related changes in the dog hypothalamic-pituitary-adrenocortical system: neuroendocrine activity and corticosteroid receptors. Lournal of Steroid Biochemistry and Molecular Biology 40:63-69.

Ricklefs, R. E., and M. Wikelski. 2002. The physiology/life history nexus. Trends in Ecology and Evolution 17:462-468.

Riechert, J., O. Chastel, and P. H. Becker. 2012. Why do experienced birds reproduce better? possible endocrine mechanisms in a longlived seabird, the common tern. General and Comparative Endocrinology 178:391-399.

Rigou, Y., and M. Guillemette. 2010. Foraging effort and pre-laying strategy in breeding common eiders. Waterbirds 33:314-322.

Romero, L. M. 2002. Seasonal changes in plasma glucocorticoid concentrations in free-living vertebrates. General and Comparative Endocrinology 128:1-24.

Romero, L. M., and J. M. Reed. 2005. Collecting baseline corticosterone samples in the field: is under $3 \mathrm{~min}$ good enough? Comparative Biochemical Physiology A: Molecular and Integrative Physiology 140:73-79.

Rowe, L., D. Ludwig, and D. Schluter. 1994. Time, condition, and the seasonal decline of avian clutch size. American Naturalist 143:698722.

Ruffino, L., P. Salo, E. Kolvisto, P. B. Banks, and E. Korpimäki. 2014. Reproductive responses of birds to experimental food supplementation: a meta-analysis. Frontiers in Zoology 11:80. doi:10.1186 /s12983-014-0080-y.

Salvante, K. G., G. Lin, R. L. Walzem, and T. D. Williams. 2007. Characterization of very low-density lipoprotein particle diameter dynamics in relation to egg production in a passerine bird. Lournal of Experimental Biology 201:1064-1074.

Salvante, K. G., and T. D. Williams. 2002. Vitellogenin dynamics during egg-laying: daily variation, repeatability and relationship with egg size. Journal of Avian Biology 33:391-398.

Sapolsky, R. M., L. M. Romero, and A. U. Munch. 2000. How do glucocorticoids influence stress responses? integrating permissive, suppressive, stimulatory, and preparative actions. Endocrine Reviews 21:55-89.
Schoech, S. J., E. D. Ketterson, and V. Nolan, Jr. 1999. Exogenous testosterone and the adrenocortical response in dark-eyed juncos. Auk 116:64-72.

Schoech, S. J., M. A. Rensel, E. S. Bridge, R. K. Boughton, and T. E. Wilcoxen. 2009. Environment, glucocorticoids, and the timing of reproduction. General and Comparative Endocrinology 163:201207.

Schultner, J., A. S. Kitaysky, J. Welcker, and S. Hatch. 2013. Fat or lean: adjustments of endogenous energy stores to predictable and unpredictable changes in allostatic load. Functional Ecology 27:45-55.

Sénéchal, E., J. Bêty, H. G. Gilchrist, K. A. Hobson, and S. E. Jamieson. 2011. Do purely capital layers exist among flying birds? evidence of exogenous contribution to Arctic-nesting common eider eggs. Oecologia 165:593-604.

Smith, H. G. 1993. Seasonal decline in clutch size of the marsh tit (Parus palustris) in relation to date-specific survival of offspring. Auk 110:889-899.

Stearns, S. C. 1992. The evolution of life histories. Oxford University Press, Oxford.

Steenweg, R. J., H. L. Hennin, J. Bêty, H. G. Gilchrist, T. D. Williams, G. T. Crossin, and O. P. Love. 2015. Sources of diel variation in energetic physiology in an Arctic breeding, diving seaduck. General and Comparative Endocrinology 216:39-45.

Stephens, P. A., I. L. Boyd, J. M. McNamara, and A. I. Houston. 2009. Capital breeding and income breeding: their meaning, measurement, and worth. Ecology 90:2057-2067.

Williams, T. D. 2008. Individual variation in endocrine systems: moving beyond the "tyranny of the golden mean." Proceedings of the Royal Society B: Biological Sciences 363:1687-1698.

- 2012. Physiological adaptations for breeding birds. Princeton University Press, Princeton, NJ.

Williams, T. D., C. G. Guglielmo, O. Egeler, and C. J. Martyniuk. 1999. Plasma lipid metabolites provide information on mass change over several days in captive western sandpipers. Auk 116:994-1000.

Wingfield, J. C., J. P. Smith, and D. S. Farner. 1982. Endocrine responses of white-crowned sparrows to environmental stress. Condor 84:399-409.

Zera, A. J., and L. G. Harshman. 2001. The physiology of life history trade-offs in animals. Annual Review of Ecology and Systematics 32:95-126.

Zera, A. J., L. G. Harshman, and T. D. Williams. 2007. Evolutionary endocrinology: the developing synthesis between endocrinology and evolutionary genetics. Annual Review of Ecology, Evolution, and Systematics 38:793-817.

Associate Editor: Elizabeth Adkins-Regan Editor: Alice A. Winn 